\title{
Differenz
}

Revista internacional de estudios heideggerianos y sus derivas contemporáneas

AÑO 6 NÚMERO 5: JULIO DE 2019. e-ISSN: 2386-4877 - DOI: 10.12795/DIFFERENZ.2019.105.09

[pp. 183-204]

\section{Cuestiones litigantes. El diálogo de Heidegger con Hegel y Schelling.}

\section{Litigating issues. Heidegger's dialogue with Hegel and Schelling.}

\author{
Jorge Eduardo Fernández ${ }^{1}$ \\ Universidad Nacional de San Martin
}

\section{Introducción}

El siguiente artículo, bajo un título un tanto pretencioso, pretende mostrar y, en el mejor de los casos, abrir la reflexión en torno a las cuestiones en la cuales Martin Heidegger sitúa su diálogo litigante con Hegel y Schelling.

La cuestión principal en la cual se centra el vínculo de Heidegger con aquello que el mismo denomina "idealismo especulativo" radica en el significado de la cópula "es". Al respecto, en Identidad y diferencia encontramos la fórmula "idealismo especulativo", acompañada de la siguiente aclaración:

“El pensamiento occidental ha precisado más de dos mil años para que la relación de lo mismo consigo mismo que reina en la identidad y se anunciaba desde tiempos tempranos, salga decididamente con fuerza a la evidencia como tal mediación, así como para encontrar un lugar a fin de

1 Protocolo del seminario "Hegel-Heidegger" impartido en la Universidad de Sevilla, el 17 de Octubre de 2018, en el marco del seminario permanente Heidegger en sus textos, organizado por el grupo de investigación Filosofía Aplicada: Sujeto, Sufrimiento, Sociedad (HUM-018). 
que aparezca la mediación en el interior de la identidad. Pues la filosofía del idealismo especulativo, preparada por Leibniz y Kant, y mediante Fichte, Schelling y Hegel, fue la primera en fundar un lugar para la esencia en sí misma sintética de la identidad. Tal lugar no puede ser mostrado aquí. Sólo hay que tener en cuenta una cosa: que desde la época del idealismo especulativo, al pensamiento le ha sido vedado representar la unidad de la identidad como la mera uniformidad y prescindir de la mediación que reina en la unidad. En donde esto ocurre, la identidad se representa de modo solamente abstracto" ${ }^{\prime 2}$.

Desde este punto de vista debemos aclarar que la temática excede nuestra intención que es la de considerarla tan solo en la relación que ella mantiene con las obras de Hegel y Schelling. El tratamiento de la proposición del fundamento en torno a Leibniz, de la tesis de Kant sobre el ser, de los seminarios sobre el idealismo especulativo, en ese caso de Fichte, queda como deuda asumida ante un planteo más amplio de la cuestión.

El único motivo que pueda justificar este cercenamiento del tema lo podrán comprender teniendo en cuenta las líneas y caminos de investigación que me han conducido al tema. En este sentido distinguiría, al menos, dos caminos que transito hace ya algunos años:

El primero de ellos, y en cierto sentido, el principal, está enmarcado en mis estudios sobre la Ciencia de la lógica de Hegel y en ella de manera especial en torno al concepto hegeliano de Dasein. Podrán suponer ya, en esta temática, un casi impuesto acercamiento y cotejo con Heidegger, o al menos con Ser y tiempo.

El segundo camino, eje temático, son mis estudios de lo que podemos comprender como período medio o, a mi parecer más adecuado, período "gozne" en el desarrollo de la obra de Schelling. Me refiero de manera especial a las Investigaciones sobre la esencia

2 "Daher kommt es, daß die Identität durch die Geschichte des abendländischen Denkens hindurch im Charakter der Einheit erscheint. Aber diese Einheit ist keineswegs die fade Leere dessen, was, in sich beziehungslos, anhaltend auf einem Einerlei beharrt. Bis jedoch die in der Identität waltende, frühzeitig schon anklingende Beziehung desselben mit ihm selbst als diese Vermittelung entschieden und geprägt zum Vorschein kommt, bis gar eine Unterkunft gefunden wird für dieses Hervorscheinen der Vermittelung innerhalb der Identität, braucht das abendländische Denken mehr denn zweitausend Jahre.Denn erst die Philosophie des spekulativen Idealismus stiftet,vorbereitet von Leibniz und Kant, durch Fichte, Schelling und Hegel dem in sich synthetischen Wesen der Identität eine Unterkunft. Diese kann hier nicht gezeigt werden. Nur eines ist zu behalten: Seit der Epoche des spekulativen Idealismus bleibt es dem Denken untersagt, die Einheit der Identität als das bloße Einerlei vorzustellen und von der in der Einheit waltenden Vermittelung abzusehen. Wo solches geschieht, wird die Identität nur abstrakt vorgestellt". HEIDEGGER, M., Identität und Differenz. Klostermann. Frankfurt am Main, 2006. p. 54. 
de la libertad humana... y a su derivación temática en las distintas formulaciones de Las edades del mundo.

Teniendo en cuenta estas aclaraciones mi exposición sobre Heidegger y el "idealismo especulativo" consistirá tan solo en la consideración de dos cuestiones que espero sean un aporte y un motivo de diálogo con ustedes. Las dos partes en las que dividiré este escrito las he titulado de este modo:

1. Heidegger y el concepto hegeliano de Dasein.

2. La influencia de Schelling en la reformulación de la proposición de identidad.

\section{Heidegger y el concepto hegeliano de Dasein}

Como podrá suponerse, llego a este tema, en principio, en el curso de una investigación sobre la Ciencia de la Lógica y, de manera especial, en ella, de la consideración del concepto hegeliano de Dasein.

El primer punto de contacto entre dicha investigación y Ser y tiempo radica en haber comprobado que, a pesar de que Heidegger hace una clara y expuesta mención a esta obra de Hegel en el inicio de Ser y tiempo, no encontramos en lo sucesivo otras referencias explicitas a la Ciencia de la lógica y menos aún al concepto de Dasein tal cual lo expone Hegel en el capítulo segundo de La doctrina del ser.

Con la publicación en el año 2011 del tomo 86 de la Gesamtausgabe de Heidegger, que contiene los seminarios que él dictara sobre Hegel y Schelling durante 1927 y 1957, se le agregan a la cuestión aportes sumamente significativos que permiten una revisión y le otorgan al tema una nueva relevancia. El tomo está conformado por los siguientes seminarios: 1-Aristóteles-Hegel. Seminare. SS. 1927. 2-Schelling über das Wesen der menscheliche Freiheit, WS. 1927/1928. 3-Hegel "Rechtsphilosophie". WS. 1934/1935. 4-Schelling und der deutsche Idealismus. 1941/1943. 5-Zu Hegel Phänomenologie des Geistes. SS. 1942. 6-Zu Hegel Logik des Wesens. WS. 1955/1956. 7-Gesprächt von der Sache des Denkens. WS. 19565/1957. Anhang I. Hegel: I.1-Phänomenologie des Geistes (SS. 1942). I.2-Zu Hegel Aesthetik. I.3-Aus: Gesprächt von der Sache des Denkens (1956/1957). I.4-Zum Text Logik I, E4 und 63/64. I.5-Schelling: [Späte Bemerkungen und Aufzeichnungen. Anhang II: Protokole und Mitschriften. Anhang III: Vorlesungen und Seminärübungen.

De manera especial, en lo que se refiere a la gesta de Ser y tiempo, encontramos que en el mismo año de su edición, 1927, Heidegger se encontraba dictando, en el semestre de verano, el recién mencionado seminario sobre Aristóteles y Hegel. Si bien el planteo del 
tema reviste, en lo que respecta a la correspondencia entre fechas, cierto anacronismo, nos parece que no resulta forzado poner en consideración la influencia de la Ciencia de Lógica, al menos en lo referente al barbecho o tiempo de maduración pensante de las cuestiones en torno a la cuales se cierne la célebre obra de Heidegger. Lo más relevante, en lo referido al curso de una investigación sobre la Ciencia de la lógica, es que Heidegger en su seminario sobre Aristóteles y Hegel se dedica, principalmente, a una interpretación de esta obra de Hegel.

Para iniciar una interpretación de lo planteado por Heidegger en dicho seminario cabe señalar, en principio, las que podemos comprender como las líneas generales de interpretación de la Ciencia de la lógica propuestas por Heidegger, para pasar luego a aquellos pasajes en los que Heidegger hace mención destacada al concepto hegeliano de Dasein.

El interés de Heidegger por Aristóteles y Hegel radica en lo que el mismo Heidegger define como la "fundamentación y tarea de la ontología aristotélica (y de los antiguos) cuyo resultado se encuentra en la Lógica de Hegel" ${ }^{3}$.

Como podemos apreciar, resulta evidente la coincidencia entre el objetivo del seminario y la tesis inicial de Ser y tiempo, que presenta a la metafísica como gigantomakia peri tes ousias, alegando que tiene su origen con Platón y Aristóteles en Atenas y que se despliega, con algunos "retoques" (übermalungen) hasta la Lógica de Hegel ${ }^{4}$. Ciertamente ésta deja de poder ser considerada una mera coincidencia y demanda un desarrollo más detallado que el que Heidegger le dedica en su seminario sobre Aristóteles y Hegel, en el cual, si bien encontramos anotaciones sumamente interesantes sobre la Ciencia de la lógica, estas indicaciones, al carecer de desarrollo, dejan demasiada tarea interpretativa al lector. No obstante, contar con estos señalamientos abre la posibilidad de poder establecer puntos de contacto y comparación entre ambas obras, la Ciencia de la lógica y Ser y tiempo.

La tarea no es sencilla no solo por las dificultades de acercamiento y de relación entre ambas obras, sino además, por la complejidad que cada una de ellas contiene. A diferencia de la Crítica de la razón pura que, cabe asumir, cuenta con una amplia gama y tradición de intérpretes que, como vemos, influyen directamente en el pensamiento de Heidegger, la Ciencia de la Lógica, cabe plantear, llega a Heidegger intacta, con toda su problematicidad de comprensión.

3 "Ankommen an der Grundfrage: welches ist das Fundament und »die" Aufgabe der Ontologie des Aristoteles (der Antike) bzw. Der Logik Hegels I wie sieht die Durchführung aus im Resultat". HEIDEGGER, M., Seminare Hegel-Schelling. GA 86. Vittorio Klostermann. Frankfurt am Main. 2011. p. 3.

4 HeIDEgGer, M., Sein und Zeit. Max Niemeyer. Tübingen, 1993. p. 2. 
Decir que la Ciencia de la lógica es una obra lo suficientemente explorada es algo que, al menos por ahora, estamos lejos de poder afirmar. Preguntarnos por ella, nosotros, desde este puñado de años del siglo XXI, indica no mucho más que la intención de dirigir nuestra mirada hacia esta obra de Hegel que ha sido editada entre 1812 y 1832 y que, según apreciaciones tan generales como la de nuestra primera intención, podemos decir que contiene el despliegue especulativo de la idea expuesto en sus tres partes: ser, esencia, concepto.

Entre nuestra mirada actual y la Ciencia de la lógica no se encuentran tan solo doscientos años, sino, principalmente, la brecha abierta por el hundimiento de la filosofía que, ante el cual, la misma Ciencia de la lógica ha acompañado con su "descenso al mundo de las sombras". Son varias las fórmulas de los intérpretes de la esta obra de Hegel que podríamos mencionar y, tanto una como otra, expresan que su tarea principal es la de cumplir el giro copernicano y transformar la metafísica en lógica. Tarea que, dado el rumbo emprendido por Heidegger, no lo deja indemne.

Pero, más allá de las complicaciones y las dificultades que atañe a esta menuda tarea, nos encontramos con ciertas líneas de acercamiento. La principal de estas líneas, me atrevo a plantear, es la de poder saber hasta qué punto la falta de distinción y por ello de necesidad de articulación entre el "ser-a-la-mano" (Zuhande) y el "ser- ante-losojos" (Vorhande), señalada por Heidegger como un déficit de la ontología aristotélica, se encuentra y afecta también a la Ciencia de la lógica.

Esta cuestión, pareciera, es la que conduce la lectura de la Lógica emprendida por Heidegger en su seminario. Ciertamente no es una cuestión menor y ha de requerir, como Heidegger pronto alcanza a comprender, plantear una tesis de lectura que abarque a la Ciencia de la lógica en su totalidad, es decir que la abra y permita dominarla en comprensibilidad, en su "pensabilidad".

Como advertimos en párrafos anteriores, la lectura que Heidegger inicia de esta obra capital de Hegel se encuentra flanqueada por los aportes neokantianos y, de manera especial, por el desplazamiento de la concepción del tiempo que va desde la Crítica de la razón pura a la obra de Hegel.

En este sentido cabe tener en cuenta dos cuestiones de importancia: La primera de ellas radica en que, además de contar con la obra de Hermann Cohen, la lectura de la Crítica de la razón pura realizada por Heidegger está concentrada, al menos en esos años, en la obra de Fritz Heinemann Der Aufbau von Kants Kritik der reinen Vernunft und das 
Problem der Zeit ${ }^{5}$. Esto lo va a situar a Heidegger, al menos al inicio del seminario, en la búsqueda de trazar un ámbito de relaciones posibles entre la lógica trascendental kantiana y la lógica especulativa de Hegel. Me animo a agregar que este es un conducto para nada despreciable y que sitúa a la Ciencia de la lógica como una instancia de mediación, que habrá que tratar de dilucidar con suma precisión en qué consiste, entre la obra de Kant y el propósito fenomenológico-hermenéutico de Heidegger.

El segundo punto a tener en cuenta nos sitúa en el núcleo de la cuestión. En su pretensión de poder pensar la Ciencia de la lógica, Heidegger ensaya anticiparla cuestionando la que él considera la idea inicial de la Ciencia de la lógica, la idea de devenir. El planteo será el siguiente: la Ciencia de la lógica se desarrolla a partir de la puesta en pensamiento del "devenir", pero no sabemos de dónde él procede. De este modo Heidegger va introduciendo al "tiempo" como lo no pensado y, por ello mismo, como el horizonte desde donde anticipar el devenir del devenir inherente a la Ciencia de la Lógica.

Párrafo aparte, respecto a esta anticipación, que sitúa al tiempo como a priori del devenir, podemos encontrar un ineludible antecedente en el propósito principal de Las edades del mundo de Schelling. Lo significativo es que no se encuentran en la obra de Heidegger, al menos fácilmente, referencias a esta obra de Schelling.

Retomando el curso del seminario sobre Aristóteles y Hegel, podemos plantear que, si la mirada puesta en la fundamentación de la ontología, mencionada en principio, nos conducía al inicio de Ser y tiempo, la introducción del tiempo como horizonte de comprensión del devenir, nos conduce hacia las páginas finales en las que Heidegger plantea el problema de la temporalidad en Hegel. La cuestión allí planteada, si bien se centra especialmente en el concepto hegeliano de tiempo expuesto en la Enciclopedia y contiene algunas referencias derivadas a la Ciencia de la lógica, pareciera quedar comprendida dentro de la organización enciclopédica que le permite a Heidegger, en último término concluir que el tiempo, concebido por Hegel como "devenir intuido" (angeschaute Werden) se define en el plano de la historización o de la "temporalidad del espíritu". La estrategia de lectura implementada por Heidegger en su seminario logra plasmarse en la medida en que logra volver comprensible la transformación de la lógica trascendental en lógica especulativa, situando al tiempo como horizonte no pensado, es decir, desde donde liberar la "pensabilidad" de la Ciencia de la lógica.

De este modo, como anticipáramos, situándose en el punto culminante de la obra de Hegel: "la doctrina de la idea", Heidegger dirige su cuestionamiento hacia el origen

5 Heinemann, F., Der Aufbau von Kants Kritik der reinen Vernunft und das Problem der Zeit. Alfred Töpelmann. Giessen, 1913. 
o procedencia del devenir como paso inicial de la Ciencia de la lógica. Desde allí comprende al devenir como la clave principal de la exposición de la obra. Para él "el devenir del devenir" en su modalización especulativa efectuada en el primer capítulo de la Ciencia de la lógica, supone al tiempo como horizonte no pensado. En sus anotaciones Heidegger retoma la línea de exposición del concepto hegeliano del tiempo tomada de la Enciclopedia y lo define, también en el seminario, con la fórmula: "tiempo-devenir intuido" (Zeit-angeschaute Werden) ${ }^{6}$. El "tiempo", en tanto lo no pensado en devenir, abre el horizonte de comprensión del devenir de la idea, horizonte en que tiempo se abre a la "cosa del pensar". Esto implica, remitiéndonos a la organización expositiva de la Ciencia de la Lógica, interpretar la doctrina de la idea como lógica del pensar.

Esta parece ser la composición topológica planteada por Heidegger: el modo de comprender la Ciencia de la lógica es el de lograr situarla en el contexto abierto por "la cosa del pensar". Esta tesis parece confirmarse después, en los años en que Heidegger seguirá situando sus lecturas de Hegel en tal contexto. La edición de estos mismos seminarios parecen avalar la idea de que el terreno donde Heidegger decide vérselas con Hegel está definido por "la cosa del pensar" (Die Sache des Denkens). En cierto sentido tenemos que reconocer que la lectura sobre Hegel iniciada en el seminario sobre Aristóteles y Hegel será retomada en el seminario que dictara en 1956 / 1957 titulado Gesprächt von der Sache des Denkens.

Es esta una línea de fuga, o al menos de distracción, entre Heidegger y la Ciencia de la lógica que tendrá su peso a la hora de comprender el ámbito del diálogo litigante con Hegel, línea que predomina en el posicionamiento de Heidegger y se vuelve definitoria de la necesidad de producir el "paso atrás" en el contexto de la constitución onto-teológica de la metafísica. La conclusión alcanzada y sostenida por Heidegger respecto a este punto es la misma que plantea al final de Ser y tiempo, donde sostiene que, para Hegel "pensar es devenir de la negación de la negación"7.

Yendo al segundo punto propuesto, a lo que corresponde específicamente al concepto de Dasein, Heidegger plantea, en el segundo parágrafo del seminario, que la Ciencia de la lógica, en tanto "doctrina de la verdad" (Lehre von der Warheit), contiene una "interpretación ontológica de la verdad", y esto ha de comprenderse como interpretación de la verdad del Dasein. Señala a su vez, que se trata de una disciplina perteneciente a la

6 HeIDEgGER, M., Seminare Hegel-Schelling. cit. p. 41.

7 lb. p. 36. 
ontología fundamental (Fundamentalontologie), es decir, de "una región de la ontología del Dasein" (ein Bezirk der Ontologie des Daseins) ${ }^{8}$.

Las referencias que Heidegger va señalando respecto al concepto hegeliano de Dasein oscilan al modo de un tanteo interpretativo que, por un lado, pareciera pretender apropiarse del curso expositivo de Hegel y, por otro, tener que responder a la literalidad del texto. Un ejemplo de ello lo encontramos en los parágrafos 22 y 23 del seminario donde vemos que Heidegger hace un punteo de las principales afirmaciones que Hegel formula respecto al Dasein en el comienzo del capítulo segundo de la Ciencia de la lógica. A partir de ello, Heidegger indica que Dasein, en tanto "ser determinado" (bestimmte Sein), es el "primer determinado" (das erste Bestimmte) con el cual Hegel inicia el pensar ${ }^{9}$. Dasein es la primera determinación del devenir, y en este sentido completa Heidegger utilizando el mismo terminología de Hegel: Dasein es "lo fáctico" (das Faktische). La cuestión que planteamos en torno a la influencia de la Ciencia de la Lógica en Ser y tiempo encuentra en la "facticidad del Dasein" su tópico de mayor cercanía y distancia, lo cual requiere un trabajo sumamente detallado y exigente al respecto.

Pretendiendo en este escrito tan solo contribuir a la mera presentación del tema, cabe mencionar la fórmula utilizada por Hegel: “Lo fáctico así como está presente (se presenta, tal como es), es el Dasein en general”10. La cual Heidegger interpreta como determinación inicial, el fáctico "horizonte indeterminado de logos y poiesis"11; para concluir sosteniendo que el Dasein es expuesto en la Ciencia de la lógica, como el fáctico fundamento óntico de la ontología, "un factum" no comprendido, lo inmediato no como el "puro ser-ante-losojos", sino "lo a la mano"12.

Luego de estas apreciaciones sobre el concepto hegeliano de Dasein, Heidegger, hacia el final de sus anotaciones del seminario, retoma la línea de su interpretación de Hegel planteada hacia el final de Ser y tiempo. En esta dirección señala que en la Ciencia de

$8 \mathrm{Ib}$. p. 4.

9 "Womit das Denken anfängt" Ib. §28. Tengamos en cuenta que esta fórmula obedece a una de las cuestiones que definen a la lógica según la comprensión de Hegel y remite al pasaje gozne que precede al desarrollo del cuerpo de la obra y que Hegel titula con la pregunta "Womit muss der Anfang der Wissenschaft gemacht Werden?".

10 "Das Faktische was also vorhanden ist, ist das Dasein überhaupt...". HEGEL, G.W.F., Wissenschaft der Logik. Die Lehre vom Sein (1832), Felix Meiner. Hamburg. 1990. p. 110.

11 "Ontologischer Horizont unbestimmt: faktisch: logos und poiesis". 11 HEIDEGGER, M., Seminare Hegel-Schelling. cit. §47.

12 "Bei Hegel einfach ein Faktum nicht verständlich gemacht an der Seinsart des Anschauens und des anschauenden Daseins. Das Unmittelbare doch gerade nicht das reine Vorhandene!, sondern das Zuhandene". Ib. 
la lógica, el "tiempo" es concebido como "devenir intuido" (angeschaute Werden), y en la misma línea agrega que, esto implica que la negación de la negación, procedente del puro devenir, es "pensar del pensar" y, de este modo, se trata de una "ontologíalógica" (Ontologie-Logik). Su problema fundamental, concluye Heidegger, coincide con la cuestión del fundamento óntico de toda ontología: la temporalidad.

Expuesto, por mi parte de manera escueta e insuficiente, este primer acercamiento al concepto hegeliano de Dasein en el seminario que Heidegger dictara en el semestre de verano de 1927, la cuestión pareciera dirigirse en la dirección de tener que poder llegar a comprender en qué grado las apreciaciones formuladas por Heidegger acerca del concepto hegeliano de Dasein constituyen un aporte para la comprensión de la génesis de Ser y tiempo. Al respecto cabe tener en cuenta ciertas cuestiones: El concepto hegeliano de Dasein es desarrollado en la Ciencia de la lógica desde la idea de una lógica ontológica (Ontologiche Logik) título que Hegel formulara por primera vez en su Enciclopedia filosófica para el curso superior, clases que dictara en Nüremberg en 1808.

Como aclara Pirmin Stekeler Weithofer en su Hegels Analytische Philosophie: "La palabra "Dasein" no es para Hegel el simple título de la inmanencia de la vida humana como lo es para Heidegger,..."13. Esto implica que, para Hegel, Dasein, abarca al "estar siendo" de todo ente y no es concebido en función de ningún ente en especial. No obstante, en el curso del Dasein, el hombre será concebido según su determinación (Bestimmung), concebida ésta, además, como "disposición" (Beschaffenheit) y "linde" (Grenze). Al respecto cabe sumar dos puntualizaciones: La primera de ellas consiste en resaltar, siguiendo en este aspecto los aportes de Wolfgang Marx, que la esfera de Dasein constituye, en tanto esfera de la finitud, el momento contraidealista del pensamiento de Hege $^{14}$. En lo que se refiere a la "determinación del hombre" en el curso del desarrollo del Dasein, tendríamos que ver en qué sentido es posible pensar la cercanía entre Hegel y Heidegger si apelamos a las obras de aquellos que desde el siglo XVIII, incluidos entre otros Goethe y Fichte, ha desarrollado han concebido la cuestión a partir de la fórmula "Bestimmung des Menschen".

Se abre aquí un tema sumamente sugerente para su investigación. Me refiero a todos los trabajos recientes que muestran la incidencia que los planteos en torno a la

13 "Das Wort "Dasein" ist bei Hegel dann nicht einfach Titel für die Inmanenz des menschlichen Lebens wie bei Heidegger, sondern spezieller für deiktisch eingeführte und in der Deixis überprüfte qualitativen Differenzierungen". STEKELER-Weithofer, P., Hegels Analytische Philosophie. Schöning. Paderborn, 1992. p. 119.

14 MARX, W., Hegel Theorie logischer Vermittlung. Frommann-Holzboog. Stuttgart, 1972. 
"determinación del hombre" surgidos a partir de la publicación homónima de Johann en Spalding en $1749^{15}$.

La principal de estas cuestiones, me atrevo a plantear, es la de poder saber hasta qué punto la falta de distinción y por ello la necesidad de articulación entre el "ser-a-la-mano" (Zuhande) y el "ser-ante-los-ojos" (Vorhande), señalada por Heidegger como un déficit de la ontología aristotélica, se encuentra también en la Ciencia de la lógica.

El planteo de esta cuestión, que en Heidegger deriva en la determinación del "entre" (Zwischen), articulador entre ambas, quedaría planteado en la Ciencia de la lógica, en el modo como Hegel concibe la "disposición" (Beschaffenheit) del Dasein"16. Una cuestión a plantear al respecto consistiría en poder determinar hasta qué punto y en qué sentido la noción hegeliana de Beschaffenheit queda comprendida por la ontología aristotélica o se aproxima al concepto heideggeriano de Dasein. Al respecto debiéramos detenernos especialmente en los parágrafos 21,22 y 23 del seminario, en los cuales, un dubitativo Heidegger, solo alcanza a cuestionarse acerca del significado que Hegel le asigna a la cualidad del Dasein comprendiéndolo como "Beschaffenheit".

Preguntarnos, con la mira puesta en la Ciencia de la Lógica y en la cuestión de la temporalidad en Hegel, según lo formula Heidegger en las páginas finales de Ser y tiempo, hasta qué punto la "facticidad" del Dasein, tal cual Hegel la plantea en la Ciencia de la lógica, se encuentra predeterminada por lo aquello Heidegger denomina "la temporalidad del espíritu".

\section{La influencia de Schelling en la reformulación de la proposición de identidad}

Quiero comenzar la segunda parte de este escrito con una cita que emparenta, al igual que otras fórmulas filosóficas, a Heidegger con Schelling. La cita, cuasi hölderliniana, está tomada de las lecciones sobre el System der Weltalter que Schelling dictara en Munich

15 A propósito, resulta interesante un artículo de Fotis Jannidis: Die Bestimmung des MenschenKultursemiotische Beschreibung einer sprachlichen Formel, en el que muestra como en los años entre 1740 and 1850 la formula "Bestimmung des Menschen" fue usada en setenta y un títulos de libros. Y, de manera especial, la publicación de Laura Anna Macor (Die Bestimmung des Menschen (1748-1800). Frommann-Holzboog. Stuttgart, 2013) quien realiza el desarrollo de la historia conceptual de esta fórmula desde 1748 al 1800 .

16 Verter "Beschaffenheit" por "disposición" resulta un tanto limitado. Para comprenderlo convendría animarnos a traducirlo por "hechura". Se trata de la disposición del Dasein para ser lo tiene que ser, su destinación diríamos. En este concepto convergen y se conforma la unidad, ónticoontológica, podríamos decir, entre Sein y Sollen. 
durante 1927 y 28 y dice así: “En el inicio es el peligro, el principio negativo y quien inicialmente no lo haya evitado, ha perdido la libertad para siempre"17.

Desde esta cercana complicidad que Heidegger mantiene con la obra de Schelling, podemos empezar diciendo algo casi obvio, el escrito de Schelling al que Heidegger le dedica su principal atención son las Philosophische Untersuchungen über das Wesen der menschlichen Freiheit und die damit zusammenhängenden Gegenstände publicada alrededor de 1809.

En lo que respecta a los escritos que Heidegger le ha dedicado al pensamiento de Schelling, contamos con las siguientes publicaciones ${ }^{18}$ : 1-GA 86. Seminare. HegelSchelling (1927). 2-GA 42. Schelling: Vom Wesen der menschlichen Freiheit (1809) (Sommersemester 1936). Schellings Abhandlung "Über das Wesen der menschlichen Freiheit...". 3-GA 49. Die Metaphysik des deutschen Idealismus. Zur erneuten Auslegung von Schelling: Philosophische Untersuchungen über das Wesen der menschlichen Freiheit und die damit zusammenhängenden Gegenstände (1809) (1941). 4-GA 28. Der deutsche Idealismus (Fichte, Schelling, Hegel) und die philosophische Problemlage der Gegenwart (Sommersemester 1929) Im Anhang: Nachschrift "Einführung in das akademische Studium" (Sommersemester 1929). 5-GA 88. Seminare: Die metaphysischen Grundstellungen des abendländischen Denkens (1937).

La incidencia del escrito sobre la libertad en el pensamiento de Heidegger, inmediatamente posterior a la publicación de Ser y tiempo es notable. Ya en el semestre de invierno de 1927/1928 Heidegger dicta una seminario con el título: Schelling y la esencia de la libertad humana. En las pocas páginas pertenecientes a este seminario Heidegger centra la cuestión en el modo como Schelling sitúa a la libertad en el seno de la divinidad (Gottheit), la cual se sustrae a toda posibilidad de ser concebida como fundamento (Grund). Dicho Seminario comienza con la siguiente cita: "Pues todo ser sólo puede revelarse en su contrario, el amor sólo en el odio, la unidad en la discordia"19.

Para poder comprender el vínculo de Heidegger con Schelling debemos, casi necesariamente, al menos en principio, explicar algunas cuestiones centrales del

17 "Am Anfange ist die Gefahr, das negative Pincip und wer sie nicht gelich anfangs mied, hat die Freiheit auf immer verloren". SCHELLING, F. W. J., System der Weltalter. Klostermann. Frankfurt am Main. 1998. p. 8.

18 La fuente de esta bibliografía es Jacinto Rivera Rosales.

19 "Denn jedes Wesen kann nur in seinem Gegenteil offenbar warden, Liebe nur in Hass, Einheit in Streit". SCHELLING, F. W. J., Investigaciones sobre la esencia de la libertad humana y los objetos con ella relacionados. Anthropos. Barcelona, 1989. p. 373-374. citado por HEIDEGGER, M., Seminare Hegel-Schelling. cit. p. 40. 
pensamiento de Schelling al respecto. De manera diferente que Hegel, Schelling es un filósofo que sigue requiriendo presentación. Friedrich Wilhelm Joseph von Schelling, un filósofo cuya gran parte de su obra aún no ha sido suficientemente estudiada, es el pensador que con mayor profundidad, más que ningún otro, incluido el mismo Nietzsche, ha alcanzado a plantear la tensión entre el carácter residual de la existencia y la libertad de ser. Este es el núcleo conceptual del que Heidegger ha abrevado con frecuencia y, me animaría a decir, desde donde brota la potente influencia schellingniana en su pensamiento. Tal carácter residual arraiga, en términos de Schelling, en el "resto irreductible" (aufgehende Rest), fondo abisal de nuestro "estar siendo" (Dasein) previo a toda determinación objetiva de la conciencia y del entendimiento. La libertad de ser encuentra en dicho "resto" el magma pulsional a priori, ciego, lo pre-sub-puesto a toda ulterior necesidad y determinación. La libertad de ser anticipa, de este modo, a todo intento de fundamentación, a toda argumentación ontológica que pretenda fundar la razón de ser en un principio necesario.

Hacia 1809 Schelling publica sus Investigaciones sobre la esencia de la libertad humana... Esta obra, de notable audacia y profundidad, se convertirá en un tópico capital para la filosofía contemporánea ya que no solo marca el derrotero del pensamiento y de la obra ulterior de Schelling, sino que resulta clave, como vamos haciendo notar, respecto al pensamiento de Martin Heidegger en la fase inmediatamente posterior a Ser y tiempo. En estas investigaciones, Schelling inicia el desarrollo de la "parte ideal" de su filosofía. Esta se diferencia, en principio, de la "parte real" correspondiente, en cierto sentido, a su filosofía de la naturaleza. La esencia de la libertad humana es comprendida, a partir de esta obra, desde su vínculo con un inicio (Anfang) anterior y más profundo que aquel que determina el fundamento necesario del conocimiento objetivo de la naturaleza. La libertad es concebida desde su vinculación con el acto inicial que precede y desfonda el fundamento de necesidad.

Oponiéndose a aquellos que acusaban a Spinoza de fatalista, Schelling sostiene que esas erróneas interpretaciones se deben a una "minoría de edad" en la comprensión del principio de identidad:

“...parece como si la libertad, que no puede mantenerse en oposición con Dios, se hundiese aquí en la identidad, se puede decir sin embargo que esta apariencia es solo consecuencia de la representación imperfecta y vacía que se tiene del principio de identidad".

De manera diferente Schelling plantea: 
"Dicho principio no expresa una unidad que girando en el circula de la igualdad no sería progresiva y por ello mismo insensible y sin vida. La unidad de este principio es inmediatamente creadora" ${ }^{20}$.

Según indica el mismo autor, la libertad brota del trasfondo pulsional del "querer" (Wollen) como "acto potenciador"21. Afirma Schelling: "Querer es (el) ser originario"22. Este es el límite y fundamento del entendimiento, "el resto irreductible"23 que lo precede y excede. Pensar un sistema de la libertad en el cual ella sea concebida como a priori de la necesidad, lo conducirá a Schelling, en estas Investigaciones, a tener que concebir la posibilidad del mal como inherente a la esencia de la libertad y al acto de revelación divino. En esta búsqueda de comprender el querer de la libertad como ser originario, Schelling pone de relieve el carácter positivo del mal. La idea en la que se apoya para avanzar en sus Investigaciones consiste en plantear la distinción entre el ser en tanto existente y el ser como fundamento de la existencia. Dice Schelling:

"La filosofía de la naturaleza de nuestro tiempo ha establecido por primera vez en la ciencia la distinción entre el ser en tanto existe, y el ser como mero fundamento (Grund) de la existencia"24.

A partir de esta distinción Schelling comienza a exponer su propio pensamiento sobre el tema. "Es el fundamento de la naturaleza que Dios tiene en sí mismo,... ...pero sin embargo [éste es] distinto de $\mathrm{El}^{\prime 25}$. La libertad radica en la posibilidad del mal que se halla en el "fundamento de la naturaleza que Dios tiene en sí". La cuestión de la identidad de Dios es planteada en torno a la mismidad (Selbheit) divina: “...lo que en Dios mismo es, no es Él mismo" ${ }^{26}$. Esto hace que la exteriorización de la naturaleza sea a la vez comprendida como un acto íntimo de autorrevelación (Selbstoffenbarung). La exteriorización de la naturaleza, y también, las edades del mundo, es decir, de la vida del espíritu, son concebidas por Schelling, no solo como un camino de ascenso del hombre hacia el absoluto, sino además y principalmente, como camino a través del cual el absoluto se va conociendo a sí mismo.

20 SCHeluing, F. W. J., Investigaciones sobre la esencia de la libertad humana y los objetos con ella relacionados. cit. p. 346.

21 "Letzte potenzierende Act". Ib. p. 350.

22 "Wollen ist Ursein". Ib.

23 “...der nie aufgehende Rest". Ib. p. 360.

24 Ib. p. 358.

$25 \mathrm{lb}$.

26 Ib. p. 359 
Esta autocomprensión de Dios surge del “...anhelo (Sehnsucht) que siente el Uno eterno de engendrarse a sí mismo"27. Este anhelo es en principio "voluntad ciega", sin entendimiento, pero que ya en su acto de querer, pulsa hacia el entendimiento. No es un querer consciente de sí mismo, sino presintiente (ahndender). Este es el límite y fundamento del entendimiento, "el resto irreductible" que lo precede y excede. En él, en este carácter residual e irreductible, Schelling encuentra la raíz abisal de la libertad humana.

Curiosamente, y no por ello menos intrigante, el camino emprendido por Schelling en las Investigaciones sobre la esencia de la libertad humana... deriva en la necesidad de exponer un sistema del tiempo. La vía de derivación parece clara, el acto inicial, comprendido como acto libre de revelación que se sobrepone a la posibilidad del mal, requiere ser comprendido además como pasaje de la eternidad al tiempo. Tratándose de una de las más creativas variaciones referidas a la relación entre tiempo y eternidad, resulta también curioso, como ya lo hemos anticipado en el primer punto de este escrito, no encontrar menciones de Heidegger a Las edades del mundo. El par tiempo-eternidad, último bastión de la dualización formalizante de la metafísica, requiere ser disuelto, superado como supuesto. La eternidad solo es en el tiempo y, ser en el tiempo, implica "mundo". En esta unidad de ser y devenir de la eternidad en el tiempo situamos los "eones" que trazan el curso de Las edades del mundo ${ }^{28}$.

El "tiempo" ya no permite ser tratado tan solo como una intuición a priori de la sensibilidad, sino que, en tanto inherente a la totalidad del sujeto, en su subjetividad y objetividad, es decir, en tanto absoluto, aparece como a priori de la necesidad, o mejor dicho como a priori hipernecesario (Übernotwendig) del par necesidad y libertad. Por ello mismo el "tiempo" es pensado en Las edades del mundo desde su vínculo con lo eterno, es decir, desde el permanente devenir de lo eterno en tiempo. El "tiempo", en el sentido absoluto que se le asigna, se encuentra vinculado a la necesidad de revelación (Offenbarung) de lo eterno, y opera, por así decirlo, como su condición a priori. El pasaje de lo eterno a tiempo es inherente, esto es determina internamente, al concepto de revelación.

Los tres éxtasis temporales, pasado, presente y futuro, conforman, en este sentido, "eones", unidades de tiempo en las que la revelación de lo eterno es representada en el mundo. De ahí que Schelling se formule, en las primeras páginas de Las edades del

$27 \mathrm{lb}$.

28 La serie de redacciones de Las edades del mundo está compuesta por tres intentos de inacabada redacción: en 1811, 1813, 1815, por los Fragmentos (Weltalter Fragment) y las lecciones dictadas en Múnich en 1827 y 1828 con el título System der Weltalter. 
mundo, la pregunta "¿cómo nace el tiempo?". Esta pregunta va dirigida hacia el "instante" en el que lo eterno se revela, es decir, comienza a ser en el tiempo. Por ello para Schelling "la verdadera eternidad no es una eternidad opuesta al tiempo, sino la eternidad que comprehende al tiempo mismo y se pone en él como eternidad" ${ }^{29}$. La eternidad solo es en el tiempo y ser en el tiempo implica "mundo". Se trata entonces de unidades de tiempo y mundo, "eones" que encuentran expresión en el término "Weltalter" traducido como "edades del mundo".

La exposición completa de Las edades del mundo debió contener tres partes: pasado, presente, futuro, pero, salvo algunas anotaciones y fragmentos, la obra en su redacción ha quedado detenida en el libro sobre el pasado. Su incompletud no le resta importancia al proyecto, pero sí requiere que nos detengamos a considerar los motivos, me refiero a los de estricta observancia filosófica, que han dejado a estos intentos de exposición de sistema en formulaciones incompletas.

Los intentos de formulación de Las edades del mundo se inician con la versión de 1811 y esta es continuada por las reformulaciones de 1813 y 1815. La idea es retomada de manera explícita en la lecciones de Múnich dictadas en 1827/1828 bajo el título System der Weltalter. Las tres versiones mencionadas conservan una estructura organizada según un esquema tripartito, en cambio, en las lecciones sobre el System der Weltalter, esta tripartición desaparece y deja su espacio a los intentos de exposición de la historia de la filosofía moderna. Las edades del mundo conforman así un período de transición que parte del incompleto y, si se quiere, fracasado esquema de exposición tripartito, y se dirige hacia aquella exposición que finalizará concibiendo a la filosofía positiva, cuya unidad se encuentra en el tránsito de la filosofía de la mitología a la filosofía de la revelación. La organicidad del sistema ha de responder a la necesidad de exponer el tiempo en su totalidad, la cual solo es posible mediante la consideración de la narración del pasado sabido, la exposición del presente conocido, y la predicción del futuro avisorado ${ }^{30}$.

En este contexto plasmado por los intentos incompletos de redacción de este fallido sistema del tiempo, Schelling alcanza a plantear la más asombrosa fórmula de expresión de tal acto inicial: "no ente a ser" que dará pie para comprender que la "libertad de ser"

29 "Die wahre Ewigkeit ist aber nicht die Ewigkeit im Gegensatz der Zeit, sondern die die Zeit selbst begreifende und in sich als Ewigkeit setzende Ewigkeit (CLXIX)-nicht das Seyn im Gegensatz des Werdens, sondern das Seyn in der ewigen Einheit mit dem ewigen Werden". SCHELLING, F. W. J., System der Weltalter. Klostermann. Frankfurt am Main. 1998. VII, p. 238 (Afor. CCXVIII).

30 "Lo pasado es sabido, lo presente conocido, lo futuro es presentido. Lo sabido es narrado, lo conocido es expuesto, lo presentido es predicho (Das Vergangene wird Gewußt, das Gegenwärtige wird erkannt, das Zukünftige wird geabndet. Das Gewußte wird erzählt, das Erkannte wird dargesteIlt, das Geabndete wird geweissagt)". SCHELLING, F. W. J., Las edades del mundo. Akal. Madrid, 2002. 
califica a dicho acto, y de ese modo precede, a toda determinación de fundamento de necesidad.

Para exponer la tensión interna a la eternidad, o vida de la divinidad, Schelling expone su teoría de las tres potencias. En la teoría de las tres potencias a la cual Schelling suma lo que él mismo llama "el concepto incrementado de no ente", encontramos desplegado el principio de identidad en el seno de la divinidad. La tensión interna a la relación entre estas tres potencias consiste en que: 1-Las tres potencias son previas a la manifestación del ente, por ello son "no-ente" (Nichtseyende). 2-Las tres tienden (treiben) a ser. 3-Solo una por vez puede ser ente, mientras las dos restantes se contraen en el "no-ente". Esto implica que no es posible una manifestación inmediata de la totalidad de la esencia del absoluto. Por el contrario, cada potencia, de a una por vez, irá manifestándose en el tiempo, determinando de ese modo las distintas edades del mundo. La primera potencia es negativa, es la contracción del absoluto hacia sí mismo, la segunda es positiva y se separa de la primera, la tercera es la unidad de las tres.

El carácter especulativo del inicio, así como también la unidad de la vida divina, es pensado por Schelling en torno a la significación de la mismidad en la vida del absoluto, previa al ente, más allá del ser.

De ahí que el verdadero sentido de la unidad que hemos afirmado al comenzar sea éste: lo mismo = x es tanto la unidad como la contraposición; o los dos contrapuestos, la potencia eternamente negadora y la potencia eternamente afirmadora, y la unidad de ambas conforman el ser primigenio único e indivisible ${ }^{31}$.

En el sentido de la primera potencia: “Dios es un eterno no, una retirada (Zurückziehung) eterna"32 hacia sí mismo. Ese sí mismo señala el "ser-en-sí" supremo, la diferencia eterna antes de todo ente. En esta potencia negadora radica la afirmación eterna de la vida divina. La segunda potencia introduce la contradicción, su fuerza afirmadora es expansiva. Desde esta segunda potencia: "Dios es el sí eterno, la expansión eterna...". Esta segunda fuerza introduce la escisión en la naturaleza divina y dispone su manifestación en el ente a un acto de decisión, "aunque sea tomado de una manera ciega". La segunda potencia introduce la contraposición y con ello la necesidad de distinguir a cada potencia según su propia naturaleza, Schelling habla de la naturaleza especial (besondere Natur) de cada

31 "Der Wahre Sinn jener anfangs behaupteten Einheit ist daher dieser: ein und dasselbe $=\mathrm{x}$ ist sowohl die Einheit als der Gegensatz; oder die beiden Entegegengesetzten, die ewig verneinende und die ewig bejahende Potenz und die Einheit beider machen das Eine unzertrennliche Urwesen aus". (1815). SCHELLING, F. W. J., System der Weltalter. cit. p. 217.

32 lb. p. 218. 
potencia. En el acto eterno de decisión ciega se pone de manifiesto el impulso primigenio a ser (Urdrang zu Seyn). Antes de la creación de la naturaleza, de su revelación en el ente, el comienzo consiste en la fuerza negadora inherente a la primera potencia: "Dios se niega a sí mismo, cierra su esencia y se retira en sí mismo" ${ }^{33}$. Por ello el inicio es negativo, no porque encierre la negación en sí, sino la propia afirmación, el amarse a sí mismo de Dios. Dice Schelling: "La noche no es el ser supremo, sino el ser primero" ${ }^{34}$.

En sentido semejante y complementario al de la cita con la que iniciamos esta segunda parte, Schelling afirma:

Pues solo en la negación reside el inicio. Todo inicio es por su naturaleza un deseo de fin (Begehren des Endes), o lo que conduce al final, y por lo tanto se niega a sí mismo como fin ${ }^{35}$.

Sin embargo, el inicio, no introduce una variante en la naturaleza divina que debiera comprenderse según un antes y un después del inicio, y esto es así porque esta relación entre las tres potencias indica un inicio eterno "que nunca deja de ser inicio". Dice Schelling: "Se trata sólo de la primera tensión del arco, no tanto como ente sino como el fundamento (Grund) para que algo sea".

Mediante ese retorno continuo al inicio y el eterno recomenzar, esa vida se hace substancia en el sentido más propio (id quod susbstat), lo que siempre permanece; el continuo impulso y mecanismo interiores, el tiempo que eternamente comienza, que eternamente deviene, que eternamente devora y vuelve a parirse una y otra vez ${ }^{36}$.

Schelling refiere la fuerza de este inicio, con el mismo entusiasmo alcanzado en los párrafos anteriores de su texto, -entusiasmo que podríamos calificar de nietzscheano, si con eso no cometiésemos un anacronismo- al "fuego infatigable" (Âkámaton pÿr) de Heráclito y a la "rueda del nacer de Dios" de Jakob Böhme ${ }^{37}$.

$33 \mathrm{lb} .223$.

$34 \mathrm{lb}$.

$35 \mathrm{lb} .224$.

36 "Durch jenes stete Zurückgehen auf den Anfang und das ewige Wiederbeginnen macht es sich zur Scubstanz im eigentlich Verstand (id quod substat), zum immer Bleibenden; es ist das beständige innere Trieb und Uhrwerk, die ewig beginnende, ewig werdende, immer sich selbst verschlingende und immer sich selbst wieder gebärende Zeit". Ib. 230.

37 "Denn das Rad der Geburts Gottes bewegete sich wieder, wie es von Ewigkeit getan hatte (Pues la rueda del nacer de Dios se movió nuevamente, como lo había hecho desde la eternidad)". BöHME, J., Aurora. Insel. Frankfurt am Main, 1992. p. 464. 
El desarrollo de las tres potencias, impregnado de teosofía y mitología, se encuentra en Las edades del mundo acompañado por un decantado propiamente filosófico. En este sentido Schelling concentra el avance filosófico de Las edades del mundo en lo que él mismo llama "concepto incrementado de no-ente". Este queda expresado en la fórmula "Nichtseyende zu Seyn", que precariamente podemos traducir: "no-ente a ser", dejando para la explicación el poder y sentido condensado en la preposición " $z u$ ".

Schelling expone a toda la influencia neoplatónica, que claramente él recoge, a un proceso de incrementación positiva. Señala que, en torno a lo "no ente" se ha generado, ya entre los griegos, una gran confusión, que llega a afectar entre otras cuestiones al modo como se ha comprendido la creación ex nihilo. Según Schelling el error consiste en identificar lo "no-ente" con la nada, quedando vedada de este modo la posibilidad de pensar la distinción entre ser y ente.

De este modo concibe Schelling el acto creador de Dios, o el movimiento propio de la primera potencia. En el acto de creación la primera potencia se manifiesta como "noente" (Nichtseyende) y de este modo se diferencia en el movimiento de contracción de su ser. Retomando el planteo de las Investigaciones, podemos decir que este acto requiere que en la naturaleza divina se encuentre la posibilidad del mal. En este punto reside el carácter negativo del inicio y también la clave de comprensión de Las edades del mundo en tanto ellas son una co-ciencia de la creación (Mitwissenschaft der Schöpfung). En ella convergen la creación divina y la libertad humana.

Hablamos del Dios necesariamente real (nothwendig Wirklichen Gottes). Éste no tiene inicio en la medida en que no tiene un inicio de su inicio. En él, el inicio es un inicio eterno, es decir, un inicio que era inicio desde toda la eternidad y que sigue siendo y que nunca deja de ser inicio ${ }^{38}$.

Este acto de creación no puede ser ni ente ni "no-ente", sino "la libertad eterna de ser", la fuerza contractiva de afirmación de Dios. "Por encima del ser solamente reside la libertad verdadera, la libertad eterna" ${ }^{\prime 39}$. Sólo a partir de ella la contradicción entre la primera y la segunda potencia puede alcanzar la unidad, tercera potencia, al modo de una "libre copertenencia" (freien Zusammengehörigkeit) ${ }^{40}$. Recordando los términos puestos en juego por Heidegger en Identidad y diferencia, no deja de llamar la atención esta coincidencia.

38 SCHeLling, F. W. J., System der Weltalter. cit. p. 225.

39 Ib. p. 234.

40 lb. p. 233. 
Queda de este modo invertida la posición dominante en la tradición del argumento ontológico, la libertad es anterior a la necesidad, "Dios no es un ser necesariamente real, sino la libertad eterna de ser"41. En esta expresión se afirma el viraje que sitúa a la libertad más allá del ser y del "no-ente". Schelling gana de este modo la primacía del espíritu, de libertad y tiempo. Pero esto no significa que él comprenda a la vida del espíritu separada de la naturaleza, y de este modo, a la libertad separada de la necesidad. Por el contrario, la libertad de ser implica la unidad de libertad y necesidad ${ }^{42}$.

La naturaleza ciega busca comprenderse en la libertad eterna de ser. Esta búsqueda es movida por el anhelo (Sehnsucht) de eternidad. El anhelo surge de la separación (Scheidung) que la decisión (Entscheidung) produce. El anhelo es la referencia (Bezug) que pulsa (Trieb) hacia la unidad.

El sometimiento a la negatividad, a lo inferior, es pues comprendido en la búsqueda de su inversión y superación. De este modo la naturaleza conserva un motor propio de automovimiento, "una fuente de libertad que no llega al acto (actus), sino que siempre se detiene en la mera posibilidad (Möglichkeit -según aclara el mismo Schelling: Potentialität)" ${ }^{\prime 3}$. Al respecto, Schelling señala que se ha alcanzado un nuevo, o mejor dicho un incrementado (gesteigerten) concepto de "no-ente"44. Como anticipamos, el concepto incrementado de "no-ente" queda expresado en la fórmula acuñada por Schelling: "Nichtseyende zu Seyn", "no-ente a ser". La fuerza expresada en esta fórmula se encuentra en la pulsión ciega contenida en la preposición " $z u$ ", que poco alcanzamos a traducir con la española "a"45. En el "zu" queda expresada la pulsión (Trieb) ciega a ser, la cual es nombrada en su forma negativa en el ansia (Sucht) de la naturaleza por conocerse y en el anhelo (Sehnsucht) de unidad.

Este descenso a la libertad como inicio originario, introduce o reintroduce en la filosofía, ideas procedentes de fuentes teosóficas y cuestiones pertenecientes a la teología trinitaria. Esto hace que debamos ser sumamente cuidadosos en nuestro intento por delimitar el alcance estrictamente filosófico de su aporte. Al respecto cabe señalar

41 lb. p. 234.

42 lb. p. 239.

43 Ib. p. 266.

44 lb. p. 267. En las Vorlesung de 1827-1828, de manera explícita en la segunda lección, Schelling plantea claramente que éste incremento está puesto en vías de superar lo negativo en lo positivo. Allí dice: "Das Wahre ist nur das Positive und besteht nur in der Überwindung des Negativen und ist als soches einer Steigerung fähig". SCHELLING, F. W. J., Schellings Werke. Comisión de la Academia de Ciencias de Baviera. 1975. p. 8.

45 Opto por esta traducción pues me parece que la preposición "a" mantiene mejor que "hacia" la direccionalidad indeterminada que la fórmula Nischtseyende zu Seyn expresa. 
que Schelling mismo ha sido consciente de esta cuestión, y más aún, su empeño por desarrollar una "filosofía positiva" está puesto en la dirección de superar el riesgo de diluir el curso y el lenguaje filosófico en las otras fuentes sapienciales. Da cuenta de ello que, no obstante el esfuerzo realizado en Las edades del mundo, la búsqueda por articular la dialéctica o filosofía negativa con la filosofía positiva continúa, aún en diferentes contextos temáticos, hasta en sus últimos escritos. Ya hacia el final de Las edades del mundo la tarea de desarrollar un sistema filosófico a partir de lo "viviente originario" (Urlebendige) es planteada como doble. Por un lado, para reintroducir en la filosofía el nexo (Zusammenhang) con la vida originaria o con el Dios vivo -nexo roto, según Schelling, por Descartes ${ }^{46}$-, es necesario recuperar los aportes de fuentes mitológicas y religiosas; por otro lado, hay que forjar su despliegue positivo mediante la reformulación de la historia de la filosofía.

A la pregunta formulada por Heidegger en Identidad y diferencia: “¿cómo ha ingresado Dios en la filosofía?", hallamos en Schelling una respuesta: los dioses ya se encontraban en la sabiduría mitológica en la que la filosofía abreva.

\section{Referencias bibliográficas:}

AlbizU, E., "Schelling y Hegel". En Hegel filósofo del presente. Almagesto. Buenos Aires, 2000.

AlbizU, E., "El eterno retorno del mito. Prolegómenos de una filosofía transespeculativa del mito". Areté. Vol. XXI, N² 2. 2009. Págs. 329-362.

BöHME, J., Aurora. Insel. Frankfurt am Main, 1992.

Bolman, F., Schelling: The Age of the World. Nueva York, 1967.

BRoWN, R., The later philosophy of Schelling: The influence Of Boehme on the Works of 1809 - 1815. Lewisburg, Bucknell U.P.

Courtine, J-F. y MARquet, J-F., Le dernier Schelling, Raison et positivité. Vrin. París. 1994

Courtine, J-F. y MARquet, J-F., Extase de la raison, Essais sur Schelling, París, Galilée, 1990.

DAVID, P., “La genealogie du temps”. en Schelling, Les âges du monde. Paris. PUF, 1992.

Duque, F., La era de la crítica. Akal. Madrid, 1998.

GreISCH, J., Ontologie et Temporalité. Presses Universitaires de France. París, 1994.

4646 SChelling, F. W. J., System der Weltalter. cit. p. 270. 
HEGEL, G.W.F., Wissenschaft der Logik. Die Lehre vom Sein (1832), Hg. Hans-Jürgen Gawoll. Felix Meiner. Hamburg. 1990.

HeGEL, G.W.F., Wissenschaft der Logik. Die Lehre vom Wesen (1813), Hg. Hans-Jürgen Gawoll. Felix Meiner. Hamburg, 1992.

HeGEL, G.W.F., Wissenschaft der Logik. Die Lehre vom Begriff (1816) Hg. Hans-Jürgen Gawoll. Felix Meiner. Hamburg, 1994.

HeIDEgGer, M., Sein und Zeit. (1927), Max Niemeyer. Tübingen, 1993.

HeIdegger, M., Seminare Hegel-Schelling. GA 86. Vittorio Klostermann. Frankfurt am Main. 2011.

Heidegger, M., Schelling y la libertad humana. Trad.: A. Rosales, Monte Ávila. Caracas, 1985.

HeIDEGGER, M., Identität und Differenz. Klostermann. Frankfurt am Main, 2006.

Heinemann, F., Der Aufbau von Kants Kritik der reinen Vernunft und das Problem der Zeit. Alfred Töpelmann. Giessen, 1913.

HorstmanN, R.-P., Die Grenzen der Vernunft. Anton Hain. Frankfurt am Main, 1991.

IBER, C., "Schellings Kritik an Hegels Konzeption der Logik als Metaphysik der Wirklichkeitbegründung". En A Noiva do Espírito: Naturaleza em Hegel. Actas del V Congreso de Sociedade Hegel Brasileira.

JAESCHKE, W. (Hg.), Der Streit um die Göttlichen Dinge, (1799-1812). Meiner. Hamburg, 1999.

LANFRAnConI, A., Krisis, eine Lekture der "Weltalter". Stuttgart. Frommann-Holzboog, 1992.

LEYTE, A., Las épocas de Schelling. Akal. Madrid, 1998.

MACoR, L. A., Die Bestimmung des Menschen (1748-1800). Frommann-Holzboog. Stuttgart, 2013.

MARX, W., Hegel Theorie logischer Vermittlung. Frommann-Holzboog. Stuttgart, 1972.

Pérez-Borbujo Álvarez, F., Schelling, el sistema de la libertad. Herder. Barcelona, 2003.

PAREYSON, L., "Schelling e lo stupore della ragiones". En Ontología de la libertà. Enaudi. Turin, 1995.

SCheluING, F. W. J., Sämtliche Werke. K. F. A. Schelling. Stutgart, 1856-1861. 
SCHELling, F. W. J., Schellings Werke. Manfred Schröter. Múnich, 1927-1954.

SCHELling, F. W. J., Schellings Werke. Hg. H. M. Baumgartner, W. G. Jakobs. Comisión de la Academia de Ciencias de Baviera. En edición desde 1975.

SCHelling, F. W. J., Schelling Philosophie der Offenbarung, 1841/42. Hg. M. Frank. Suhrkamp. Frankfurt am Main, 1977.

Schelling, F. W. J., System der Weltalter. Hg. Siegbert Peetz. Klostermann. Frankfurt am Main. 1998.

SCHELLING, F. W. J., Weltalter-Fragmente. Schellingniana 13.1 y 13.2. Hg. Klaus Grotsch. Frommann-Holzboog. Stuttgart, 2002.

SCHELLING, F. W. J., Investigaciones sobre la esencia de la libertad humana y los objetos con ella relacionados. Trad. H. Cortés y A. Leyte. Anthropos. Barcelona, 1989.

SCHelling, F. W. J., Las edades del mundo. Tr. J. Navarro Pérez. Akal. Madrid, 2002.

SIEP, L., Praktische Philosophie im Deutschen Idealismus, Frankfurt am Main, 1992.

Stekeler-Weithofer, P., Hegels Analytische Philosophie. Schöning. Paderborn, 1992.

TILLIETtE, X., Schelling. Une philosophie en devenir. París, Vrin. 1970.

WIELAND, W. Schellings Lehre von der Zeit. Winter. Heidelberg. 1956.

ŽIŽEK, S., El resto indivisible. Godot. Buenos Aires, 2016. 